\title{
随州陨石中铬铁矿和谢氏超晶石的产状和 矿物化学
}

谢先德 ${ }^{*}$, 陈鸣, 王春云

中国科学院广州地球化学研究所, 广州 510640

*E-mail: xdxie@gzb.ac.cn

收稿日期: 2010-04-26; 接受日期: 2010-09-18

国家自然科学基金项目(批准号: 40772030)资助

摘要本文利用多种近代微矿物学技术, 对随州陨石中铬铁矿和谢氏超晶石的产状和矿物化 学进行了研究, 发现了 3 种产出类型的铬铁矿, 即粗粒铬铁矿、斜长石熔体池中的铬铁矿集合体 簇团和橄榄石晶体中的片状出溶铬铁矿. 前两种类型的铬铁矿在化学成分上完全相同, 但出溶铬 铁矿的成分不均一, $\mathrm{Al}_{2} \mathrm{O}_{3}$ 含量变化明显. 谢氏超晶石是不久前在随州陨石中发现的一种超尖晶 石结构新矿物, 它是由铬铁矿高压相变形成的一种具 CT 结构的高压多形. 在随州陨石中谢氏超 晶石也有 3 种产出类型, 即熔脉内的单相粗粒谢氏超晶石、熔脉边上由谢氏超晶石内带 $+\mathrm{CF}$ 结构 相中间带+铬铁矿外带组成的三相颗粒，以及熔脉内由谢氏超晶石分别与玲根石、林伍德石或镁 铁榴石等硅酸盐高压相矿物组成的两相颗粒. 在两相颗粒中, 谢氏超晶石与硅酸盐高压相矿物间 的分界线有轻到中度的弯曲, 表明硅酸盐矿物曾发生过局部甚至整体的熔融. EPMA 和 EDS 的分 析结果显示, 单相和三相颗粒中的谢氏超晶石, 在成分上与脉外的铬铁矿完全相同, 但在两相颗 粒中, 谢氏超晶石与硅酸盐高压相矿物之间则发生过明显的组分交换: 少量的 $\mathrm{Al}^{3+}$ 从玲根石和少 量的 $\mathrm{Fe}^{2+}$ 从林伍德石向谢氏超晶石扩散, 而微量的 $\mathrm{Cr}^{3+}$ 则从谢氏超晶石向玲根石或林伍德石扩 散. 在谢氏超晶石十镁铁榴石的双相颗粒中, 镁铁榴石的母矿物斜方辉石已全熔, 并与周围的熔 脉硅酸盐熔体已有相当程度的混合, 致使其晶出的石榴子石相中 $\mathrm{SiO}_{2}$ 和 $\mathrm{MgO}$ 含量明显下降, 而 $\mathrm{Al}_{2} \mathrm{O}_{3}$ 和 $\mathrm{CaO}$ 的含量则急剧增高. 熔脉中两相颗粒在矿物化学上的复杂化, 可以用冲击熔脉的温 度 $\left(1800 \sim 2000^{\circ} \mathrm{C}\right)$ 大大高于陨石未熔主体的温度 $\left(\sim 1000^{\circ} \mathrm{C}\right)$ 和硅酸盐矿物的密度 $\left(2.6 \sim 3.3 \mathrm{~g} / \mathrm{cm}^{3}\right)$ 都 比铬铁矿 $\left(4.43 \mathrm{~g} / \mathrm{cm}^{3}\right)$ 要低, 对冲击波的阻抗能力明显低于铬铁矿来解释, 因为冲击波易从高阻抗 物质向低阻抗物质反射, 使后者局部甚至整体熔融, 并引起颗粒内元素在两相之间的扩散, 甚至 使斜方辉石与颗粒外的熔体发生组分的交换.

铬铁矿在普通球粒陨石中是一种常见的具尖晶 石结构的不透明矿物. Ramdohr ${ }^{[1,2]}$ 根据该矿物的结构
和共生组合特征, 将普通球粒陨石中的铬铁矿产状 分为 6 种不同的类型: 1) 粗粒铬铁矿;2) 铬铁矿集合

英文引用格式: Xie X D, Chen M, Wang C Y. Occurrence and mineral chemistry of chromite and xieite in the Suizhou L6 chondrite. Sci China Earth Sci, 2011, doi: 10.1007/s11430-011-4199-9 
体簇团；3）假像铬铁矿；4）出溶铬铁矿；5）铬铁矿 球粒；6）蠕状铬铁矿. 粗粒铬铁矿类型多以自形或 半自形粗颗粒, 与硅酸盐基质一起, 产于绝大多数的 普通球粒陨石、无球粒陨石、石铁陨石和铁陨石中. 铬铁矿集合体簇团通常由包埋于斜长石中的中细粒 自形或半自形铬铁颗粒组成. 普通球粒陨石中的出 溶铬铁矿和铬铁矿球粒都很少见, 铬铁矿球粒多富 铬, 其总成分中 $\mathrm{Cr}_{2} \mathrm{O}_{3}$ 的含量 $>13 \mathrm{wt} \%$. 假像铬铁矿 类型仅见于普通球粒陨石的球粒内, 而蠕状铬铁矿 类型看来也仅见于中陨铁和铁陨石中. Rubin ${ }^{[3]}$ 在对 76 块平衡的 H, L 和 LL 群球粒陨石进行研究后, 提 出了有些铬铁矿是以铬铁矿-斜长石互生体产出的观 点, 并认为它们就是 Ramdohr 所说的斜长石中铬铁 矿集合体簇团. 近期有报道说, 铬铁矿在普通球粒陨 石中的丰度是随着岩石类型的增大而增加, 其平均 成分也是随岩石类型而变化, 其中铬铁矿的成分随 着变质程度的增高变得更为均匀 ${ }^{[4]}$.

相对于地球上铬铁矿的大量成分数据来说, 球 粒陨石中铬铁矿的成分数据报道就少得多. 早期的 陨石中铬铁矿的成分分析是由 $\operatorname{Tassin}^{[5]}$ 在 1908 年完 成的. Bunch 等 ${ }^{[6]}$ 于 1967 年对 12 个 H-群、6个 L-群 和 4 个 LL-群的球粒陨石中的铬尖晶石做了化学分析. 上世纪 60 年代, Jérémine 等 ${ }^{[7]}$ 和 Buseck 等 ${ }^{[8]}$ 较早利用 电子探针技术, 分别分析了 Dosso 和 Farmington 球粒 陨石中的铬铁矿成分. 随后, Snetsinger 等 ${ }^{[9]}$ 也对 7 个 “平衡的”球粒陨石中的铬铁矿做了电子探针成分分 析, 查明在每一个测定的陨石中, 铬铁矿颗粒的成分 都非常相似, 也未见有分带现象. 不过, 从一个陨石 到另一陨石, 铬铁矿还是表现出不大的成分变化范 围: $\mathrm{Cr}_{2} \mathrm{O}_{3} 54.6 \mathrm{wt} \% \sim 57.0 \mathrm{wt} \%, \mathrm{Al}_{2} \mathrm{O}_{3} 5.2 \mathrm{wt} \% \sim 6.3$ wt $\%, \mathrm{TiO}_{2} 2.08 \mathrm{wt} \% \sim 2.98 \mathrm{wt} \%, \mathrm{FeO} 30.5 \mathrm{wt} \% \sim 33.9$ wt $\%, \mathrm{MgO} 1.54 \mathrm{wt} \% \sim 2.48 \mathrm{wt} \%, \mathrm{MnO} 0.65 \mathrm{wt} \% \sim 1.05$ $\mathrm{wt} \%, \mathrm{~V}_{2} \mathrm{O}_{3} 0.65 \mathrm{wt} \% \sim 0.77 \mathrm{wt} \%$, 表明陨石中的铬铁矿 比地球上大多数的铬铁矿含有较高的铁和钛, 以及 较低的铝.

随州陨石于 1986 年 4 月 15 日陨落于湖北省随州 市东南方 $12.5 \mathrm{~km}$ 处的大堰坡. 该陨石属 L6 型球粒 陨石, 由橄榄石、低钻辉石、斜长石、铁纹石、镍纹 石、陨硫铁、铬铁矿、钛铁矿、白磷钻石和氯磷灰石 等矿物组成 ${ }^{[10]}$. 随州陨石是其母体在 30 万年前的一 次撞击事件中被碎裂成形成的 ${ }^{[11]}$. 正是由于这次撞 击事件, 随州陨石的矿物中产生了明显的冲击效应, 如橄榄石和辉石中的多组面性裂隙、橄榄石颗粒的镶
嵌块化, 斜长石中出现变形面性页理和大多数斜长 石颗粒熔融成熔长石等中、强程度的冲击特征, 以及 在陨石体中出现了数条冲击形成的黑色细熔脉, 冲 击熔脉中含有两组高压矿物组合, 即由林伍德石、镁 铁榴石、阿基莫石(akimotoite)、玻璃态的钙钛矿、玲 根石(具锰钡矿结构的 $\mathrm{NaAlSi}_{3} \mathrm{O}_{8}$ )、涂氏磷钙石等组成 的粗粒矿物组合和由镁铁-镁铝石榴子石固熔体、镁方

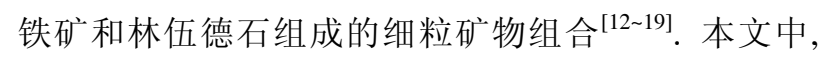
我们把随州陨石中由冲击产生的熔融细脉简称为 “熔 脉”, 而将该陨石绝大部分虽也经受过冲击, 但没有发 生熔融的球粒陨石质岩石称为“陨石未熔主体”。

铬铁矿是具尖晶石结构的矿物, 它在随州陨石 未熔主体部分的含量约为 $1.4 \mathrm{vol} \%$, 说明该陨石中铬 铁矿的丰度在 L6 群陨石中是相当高的, 铬铁矿的成 分也应是相当均匀的. 我们在随州陨石未熔主体部 分共发现 3 种产状的铬铁矿, 即粗粒铬铁矿、包裹在 熔长石中的铬铁矿微粒集合体群簇和橄榄石中的出 溶铬铁矿。

不久前, Chen 等 ${ }^{[20 ~ 22]}$ 在随州陨石熔脉内和熔脉 边上发现了两种铬铁矿的超尖晶石结构高压多形, 即具 $\mathrm{CaTi}_{2} \mathrm{O}_{4}$-结构的 CT 相和具 $\mathrm{CaFe}_{2} \mathrm{O}_{4}$-结构的 CF 相, 前者已命名为谢氏超晶石, 后者尚未命名. 这两 种高压多形均属斜方晶系, 但结构有差异. 谢氏超晶 石在熔脉中也有三种产状, 即熔脉中的粗粒单相谢 氏超晶石颗粒和由谢氏超晶石与一种硅酸盐矿物的 高压相组成的两相颗粒, 以及熔脉边上由谢氏超晶 石 $+\mathrm{CF}$ 相 + 铬铁矿组成的三相颗粒. 在本文中, 我们 详细地报道了随州陨石中铬铁矿和谢氏超晶石的各 种产状特征和对它们进行矿物化学研究的结果, 期 望通过研究能对它们的形成机制做出合理的解释.

\section{1 实验技术}

首先选取新鲜的不含熔脉和含有熔脉的随州陨 石样品分别切制成两面抛光薄片, 用偏反两用岩石 显微镜和 Hitachi S-3500N 型扫描电子显微镜(背散射 电子模式)对薄片中的矿物组合和构造进行研究. 用 Renishaw-2000 型拉曼谱仪测定薄片中矿物的拉曼光 谱, 测定时由一台光学显微镜将激发光束 $\left(\mathrm{Ar}^{+}\right.$激光, $514 \mathrm{~nm}$ 线)聚焦到 $2 \mu \mathrm{m}$ 宽大小, 并收集拉曼信号. 收集时间为 $120 \sim 150 \mathrm{~s}$, 激光能量为 $26.8 \mathrm{~mW}$.

铬铁矿和谢氏超晶石的化学成分用 Cameca 
SX-51 型电子探针的波长色散分析测定, 加速电压为 $15 \mathrm{kV}$, 样品电流为 $10 \mathrm{nA}$, 而陨石中包裹在熔长石内 以集合体群簇形式产出的铬铁矿微细颗粒, 以及熔 脉中由高压矿物组成的两相颗粒, 则用 Hitachi S-3500N 型扫描电子显微镜装置的 Link ISIS 300 型 能谱仪进行成分测定.

2 随州陨石未熔主体中铬铁矿的产状和成 分

随州陨石中的铬铁矿是一种常见的副矿物. 在 陨石未熔主体部分, 铬铁矿主要以单一相的粗颗粒 形式产出, 铬铁矿微粒集合体群簇也常见于冲击熔 融的斜长石团粒中, 而出溶铬铁矿则很少见, 我们仅
在一个橄榄石晶体中观察到少数几条微细条纹状的 出溶铬铁矿. 现将上述 3 种类型铬铁矿的产状特征和 化学成分叙述如下.

\section{1 粗粒铬铁矿的产状和成分}

随州陨石未熔主体中的铬铁矿主要以粒径小于 $50 \mu \mathrm{m}$ 的半自形和他形颗粒的形式产出, 也能观察到 长达 $100 \mu \mathrm{m}$ 的铬铁矿自形晶体(图 1(a), (b)). 有时, 几个铬铁矿颗粒聚集在一起形成一个集合体(图 1(c)). 在单个铬铁矿颗粒上常见有比与其相邻的辉石或橄 榄石要多得多的不规则裂隙, 还能观察到 2 4 组相互 平行的面性裂隙(图 1(a)). 图 1(d)显示两个受到强烈 冲击已碎裂化的铬铁矿颗粒，可见其中的数组面性 裂隙，而图的右上部位已被碎裂成许多长 0.2 30 $\mu \mathrm{m}$
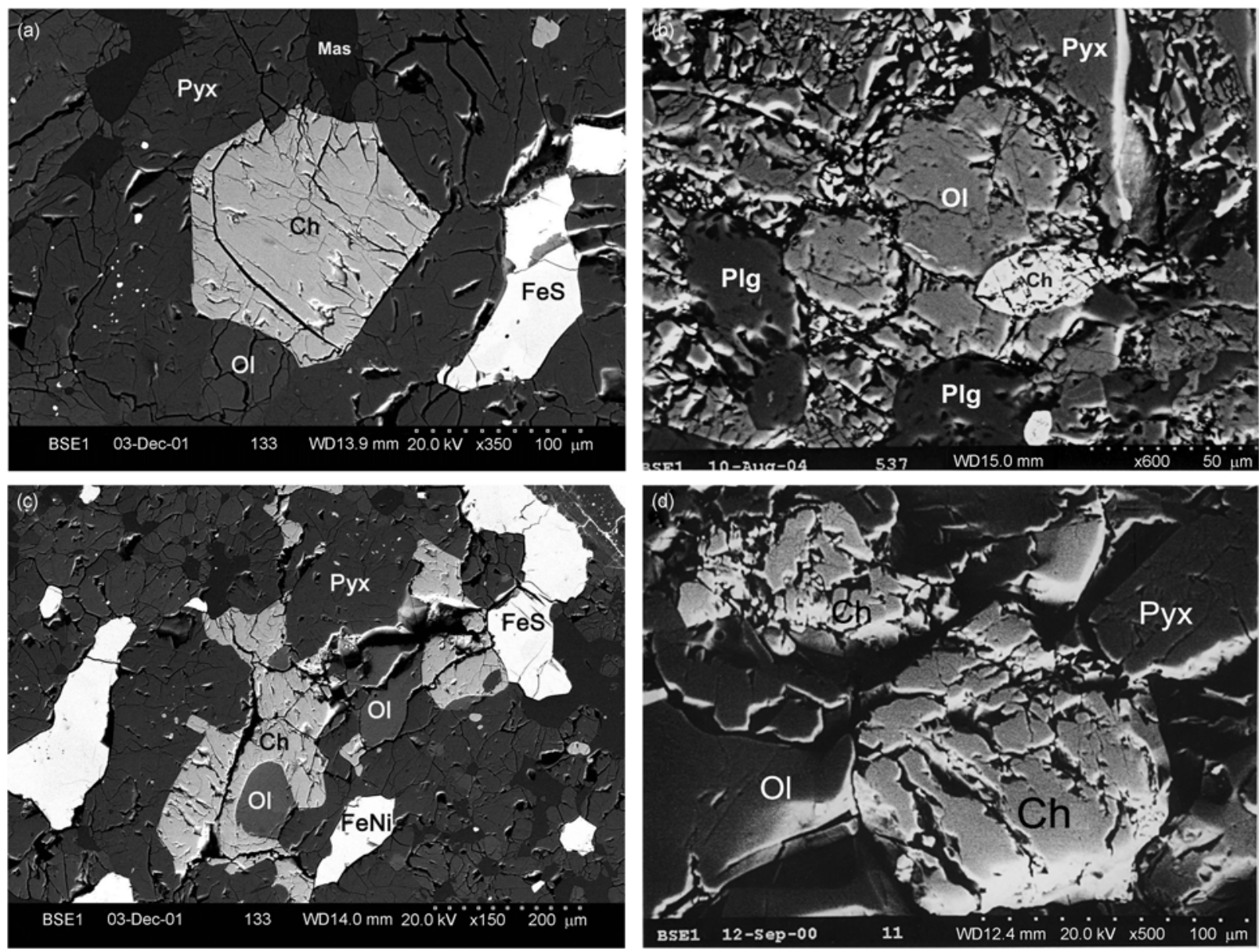

图 1 随州陨石中粗粒铬铁矿的背散射电子(BSE)图像

(a) 具面性裂隙的自形铬铁矿 (Ch)颗粒; (b) 与橄榄石 (Ol)共生的具面性裂隙的椭圆形铬铁矿颗粒; (c) 数个铬铁矿颗粒组成的集合; (d) 两个 严重破碎的铬铁矿颗粒. Pyx=辉石; Plg=斜长石; Mas=熔长石; $\mathrm{FeNi}=\mathrm{FeNi}$ 金属; FeS=陨硫铁 
大小的小碎片, 其中较大的碎片上还可见到他们仍 保留着原来的定向, 但大多数小碎片则变得杂乱无 章. 在图的中上部位见有一条穿过该铬铁矿颗粒的 滑移线, 线上下的碎片最大移动量达 $30 \mu \mathrm{m}$ 左右. 应 该指出的是, 在我们用光学显微镜和 SEM 研究过的 所有铬铁矿颗粒中, 均未曾观察到有分带的现象.

随州陨石未熔主体中 8 个单一相铬铁矿颗粒的 电子探针成分分析结果列于表 1 , 其中前 5 个是我们 分析的结果, 后 3 个则是前人的分析结果 ${ }^{[10]}$. 从该表 可知: 1) 所有 8 个铬铁矿颗粒的化学成分都非常接近; 2) 颗粒与颗粒间成分变化的范围比较窄, 如 $\mathrm{Cr}_{2} \mathrm{O}_{3}$ $56.52 \mathrm{wt} \% \sim 58.12 \mathrm{wt} \%, \mathrm{Al}_{2} \mathrm{O}_{3} 5.15 \mathrm{wt} \% \sim 6.38 \mathrm{wt} \%$, $\mathrm{TiO}_{2} 2.30 \mathrm{wt} \% \sim 3.11 \mathrm{wt} \%$, FeO $29.77 \mathrm{wt} \% \sim 31.71 \mathrm{wt} \%$, $\mathrm{MgO} 2.09 \mathrm{wt} \% \sim 2.73 \mathrm{wt} \%, \mathrm{MnO} 0.48 \mathrm{wt} \% \sim 0.99 \mathrm{wt} \%$, $\mathrm{V}_{2} \mathrm{O}_{3} 0.87 \mathrm{wt} \% \sim 1.03 \mathrm{wt} \%$; 3) 随州陨石中单一相铬铁
矿颗粒的平均化学成分, 总体上正好落在 Snetsinger 等 ${ }^{9}$ 对 “平衡型”球粒陨石中铬铁矿的成分范围之内, 仅有的小差别表现在 $\mathrm{FeO}$ 的含量 $(29.97 \mathrm{wt} \%)$ 略低于 其平均范围 (30.3 wt \% 33.9 wt \%), 而 $\mathrm{V}_{2} \mathrm{O}_{3}$ 的含量 (0.94 wt\%) 略高于其平均范围(0.65 wt \% 0.77 wt\%).

2.2 铬铁矿集合体簇团在斜长石熔体池内的产状 和成分

随州陨石未熔主体中铬铁矿的第二种产状是以 包裹在熔融斜长石(熔长石)熔体池中的集合体簇团 形式产出的. 图 2 展示了 1 号斜长石熔体池中包裹的 铬铁矿碎片分布较为杂乱的簇团，铬铁矿碎片的大 小不规则, 一般变化于 $0.4 \sim 3 \mu \mathrm{m}$, 有几个大碎片的长 度则达到 8 11 $\mu \mathrm{m}$ (图 2(b)). 大多数碎片为不规则的 圆形或椭圆形，表示碎片曾经受过局部熔融现象，在

表 1 随州陨石中粗粒铬铁矿的电子探针成分分析结果 ${ }^{a)}$

\begin{tabular}{|c|c|c|c|c|c|c|c|c|c|}
\hline 颗粒号 & 1 & 2 & 3 & 4 & 5 & $6^{*}$ & $7 *$ & $8^{*}$ & 平均 \\
\hline $\mathrm{MgO}$ & 2.52 & 2.60 & 2.73 & 2.58 & 2.67 & 2.09 & 2.46 & 2.33 & 2.50 \\
\hline $\mathrm{FeO}$ & 29.77 & 29.63 & 29.27 & 29.60 & 29.35 & 31.71 & 30.39 & 30.04 & 29.97 \\
\hline $\mathrm{MnO}$ & 0.73 & 0.83 & 0.91 & 0.81 & 0.99 & 0.48 & 0.88 & 0.59 & 0.78 \\
\hline $\mathrm{CaO}$ & n.d. & n.d. & n.d. & n.d. & n.d. & 0.12 & 0.10 & 0.00 & 0.03 \\
\hline $\mathrm{TiO}_{2}$ & 2.96 & 2.81 & 3.11 & 3.06 & 2.83 & 2.30 & 2.76 & 2.66 & 2. 81 \\
\hline $\mathrm{Cr}_{2} \mathrm{O}_{3}$ & 57.01 & 56.62 & 57.06 & 56.64 & 56.74 & 56.60 & 56.52 & 58.12 & 56.93 \\
\hline $\mathrm{Al}_{2} \mathrm{O}_{3}$ & 6.17 & 6.26 & 6.38 & 6.37 & 6.26 & 6.06 & 5.15 & 5.69 & 6.10 \\
\hline $\mathrm{V}_{2} \mathrm{O}_{3}$ & 0.87 & 0.93 & 0.90 & 0.95 & 0.89 & 1.02 & 1.03 & 0.95 & 0.94 \\
\hline 合计 & 100.03 & 99.96 & 99.68 & 100.01 & 99.73 & 100.38 & 99.29 & 100.38 & 99.93 \\
\hline
\end{tabular}

a) n.d., 未检出; *引自文献[10]. 单位: wt\%
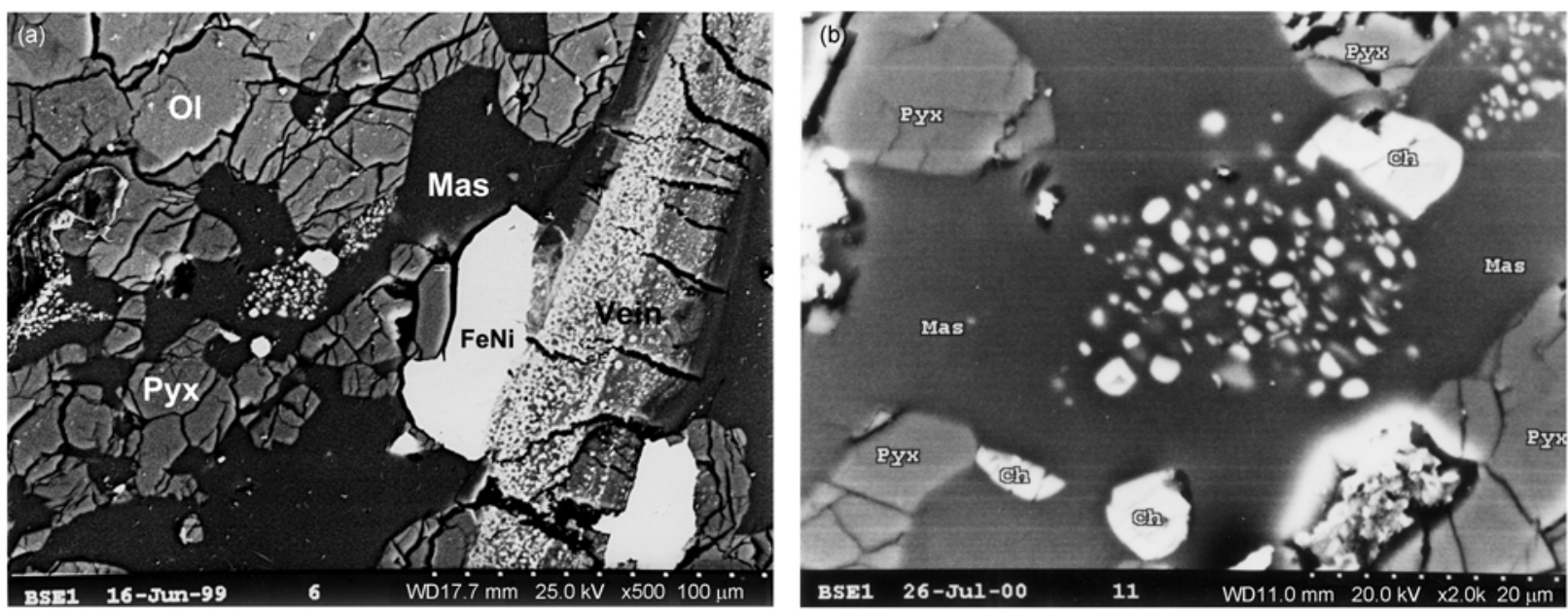

图 21 号斜长石熔体池的 BSE 图像

(a) 熔长石(Mas，黑色)中的铬铁矿碎粒集合体簇团(白色); (b) 图(a)中心部位的放大像(引自文献[12]), 图中 3 个较大铬铁矿(Ch)碎块中的原 有粒内裂隙仍明显可见. Vein 表示冲击熔脉 
几个大碎片中还可见到原来铬铁矿颗粒的部分轮廓, 以及颗粒中原有的粒内裂隙(图 2(b)). 上述现象说明, 1 号斜长石熔体池中的这些碎片很像是由一个母体铬 铁矿颗粒经受冲击后被碎裂成大小不同的碎片, 这 些碎片被就近的斜长石熔体捕获, 并在流动的熔体 中被分散开来，形成了较为杂乱的集合体簇团.

在 2 号斜长石熔体池中, 被熔长石包裹的铬铁矿 已粉碎成 $0.5 \mu \mathrm{m}$ 大小的碎片, 形成了一种很特殊的
景象, 即由成百上千个形态各异的铬铁矿微粒组成 的集合体簇团，占据了斜长石熔体池大部分体积(图 3(a)). 仔细观察, 可见这些铬铁矿微粒的大小还是变 化于 0.2 5 $\mu \mathrm{m}$ 之间(图 3(b)). 这种特殊的铬铁矿集合 体簇团在随州陨石中虽不普遍，但有时还是能观察 到的. 图 4(a)的左下方就是又一个类似的例子，只是 熔体池被压成长条形，但包裹在其中的铬铁矿集合 体簇团的产状特征与图 2(a)完全相似. 我们推测,
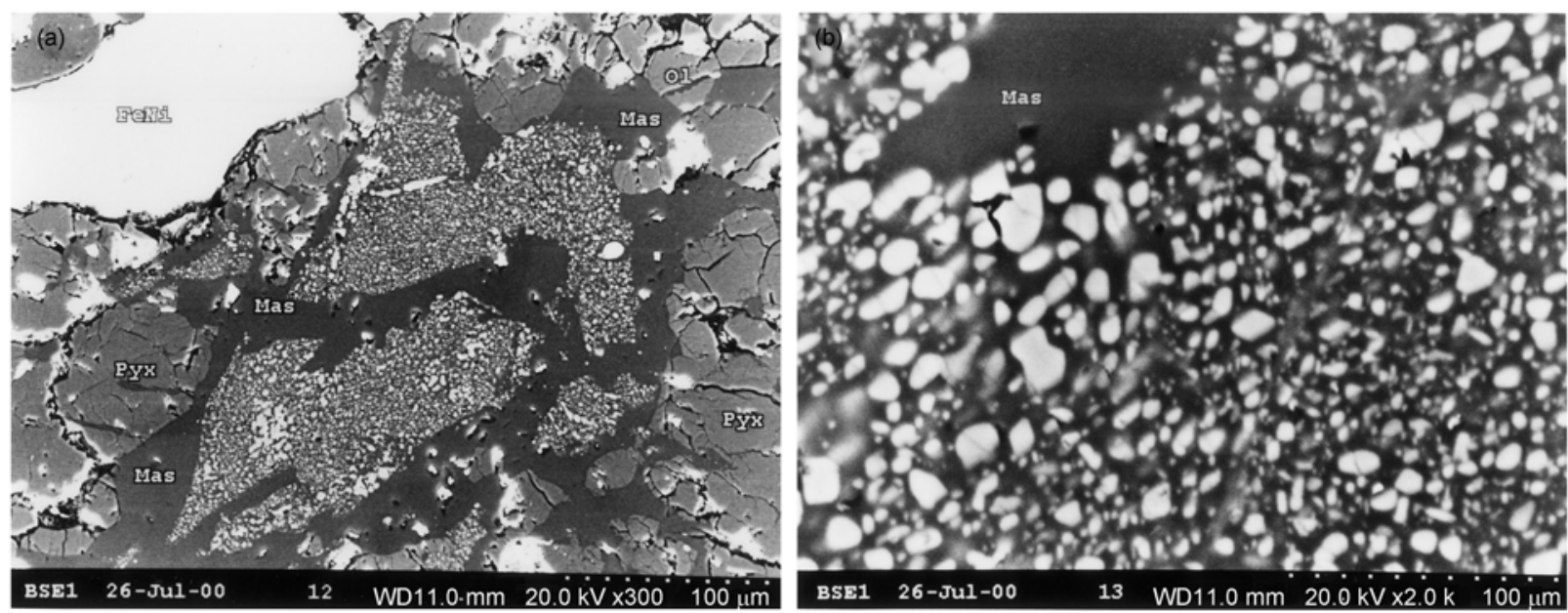

图 32 号斜长石熔体池的 BSE 图像

(a) 2 号斜长石熔体池的全貌, 示熔长石(Mas, 黑色)中的高度破碎的铬铁矿集合体簇团(白色), 引自文献[12]; (b) 图(a)中心部位的放大图像, 注意铬铁矿微粒的圆形、长方形、菱形和不规则形轮廓, 以及颗粒大小 $0.2 \sim 5 \mu \mathrm{m}$ 之间的巨大变化. Ol=橄榄石
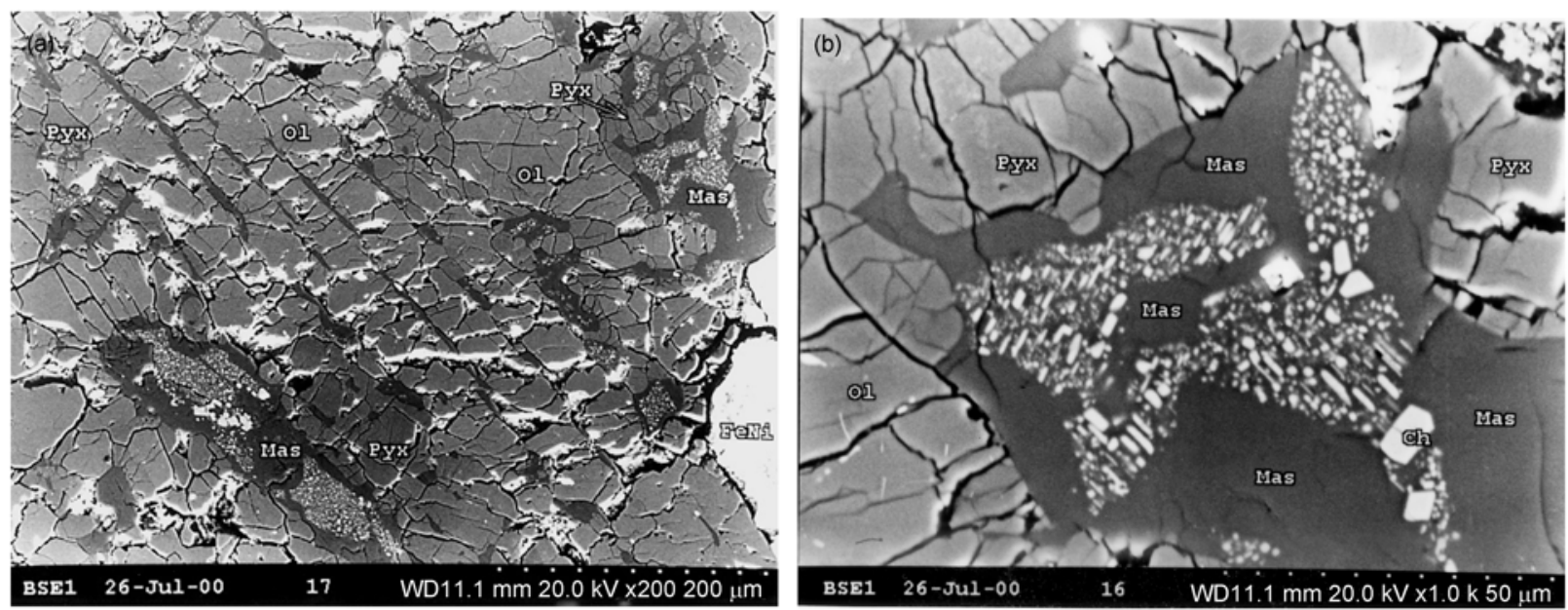

图 43 号斜长石熔体池及相邻部位的 BSE 图像

(a) 熔长石(Mas, 黑色)熔体池中高度破碎的铬铁矿集合体簇团(白色)及充填于平行裂隙中的斜长石细熔脉, 3 号斜长石熔体池位于该图右上 方; (b) 3 号斜长石熔体池的放大图像. 可见熔体池中的长条形铬铁矿颗粒具有两个方位的定向. 注意熔体池中较大的铬铁矿颗粒具有长方形 或菱形外貌 
这一特殊产状的斜长石熔体池, 有可能就是 Ram$\mathrm{dohr}^{[1]}$ 所指普通球粒陨石中变了形的铬铁矿-斜长石 球粒.

我们还要举出一种有趣的、在随州陨石中仅观察 到一次的 3 号斜长石熔体池中铬铁矿产出的特殊现 象, 该熔体池中长 $3 \sim 5 \mu \mathrm{m}$ 、宽 1 2 $\mu \mathrm{m}$ 的长条形铬铁 矿碎片显示有明显的择优定向(图 4(a), (b)). 我们认 为, 此现象是因原来的铬铁矿颗粒受冲击后, 沿着两 组发育良好的平行裂隙碎裂开来, 并很快被侵入的 斜长石熔体就地混合而固定下来的 ${ }^{[12]}$. 图 4(b) 的右 中部和右下方可见到几个较大的长方形的铬铁矿颗 粒, 长 5 9 $\mu \mathrm{m}$, 它们和大量细小的碎片都应该是从 原来铬铁矿颗粒上同时碎裂和分散开来的产物.

电子探针分析表明, 随州陨石未熔主体中斜长 石矿物为奥长石成分, 化学式为: $\left(\mathrm{Na}_{0.77} \mathrm{~K}_{0.08} \mathrm{Ca}_{0.11^{-}}\right.$ $\left.\mathrm{Fe}_{0.02}\right)_{0.98} \mathrm{Al}_{1.01}\left(\mathrm{Si}_{2.91} \mathrm{Al}_{0.09}\right)_{3.00} \mathrm{O}_{8}$, 而陨石主体中由斜长 石转变形成的熔长石与未熔的斜长石在成分上是相 似的, 其化学式为 $\left(\mathrm{Na}_{0.73} \mathrm{~K}_{0.06} \mathrm{Ca}_{0.10} \mathrm{Fe}_{0.02}\right)_{0.91} \mathrm{Al}_{1.03}$ $\left(\mathrm{Si}_{2.92} \mathrm{Al}_{0.08}\right)_{3.00} \mathrm{O}_{8}{ }^{[12]}$. 由于颗粒细小, 我门仅用能谱 (EDS)技术, 对熔体池中的熔长石和铬铁矿碎片的成 分进行了分析, 目的是了解在铬铁矿碎裂和与熔长 石混合过程中有否化学成分上的变化. 为便于比较, 我们也对随州陨石未熔主体中斜长石成分进行了相 应的 EDS 分析.
图 2(b)上的 1 号熔体池、图 3(b)上的 2 号熔体池 和图 4(b)上的 3 号熔体池中的熔长石的 EDS 分析结 果表明, 3 个熔体池中熔融斜长石的化学成分几乎完 全一样, 它们与陨石未熔主体中斜长石的成分都很 接近(表 2). 包裹在这几个熔体池中的铬铁矿碎片的 成分也十分相似(表 3 5). 我们还发现，与熔长石混 合的、颗径不同的铬铁矿碎片在成分上同样是很相似 的(表 3 5). 这就说明, 熔长石和被它捕获的铬铁矿 碎片, 分别与陨石未熔主体中的斜长石和铬铁矿具 有相同的化学成分, 在斜长石冲击熔融过程中这两 种矿物相之间没有出现化学元素的交换. 陨石主体 中单个铬铁矿颗粒和熔长石熔体池中的铬铁矿碎片, 在 $\mathrm{Cr}_{2} \mathrm{O}_{3}, \mathrm{FeO}, \mathrm{SiO}_{2}$ 和 $\mathrm{Al}_{2} \mathrm{O}_{3}$ 等组分上具有相同的含 量, 这就给我们关于 3 号熔体池中具择优定向的铬铁 矿集合体簇团, 可能是由一个铬铁矿颗粒碎裂而成 的推断有力的支持.

\section{3 橄榄石晶体中出溶铬铁矿的产状和成分}

在普通球粒陨石中, 出溶铬铁矿很少见. 这一类 型的铬铁矿仅存在于富单斜辉石的球粒中, 以细粒 铬铁矿笶团的形式产在单斜辉石和斜长石的边界部 位 ${ }^{[1]}$. Ramdohr ${ }^{[2]}$ 认为它们是从富铬的硅酸盐熔体中 出溶形成的. 然而, 我们在随州陨石中没有发现上述 产状的铬铁矿，但我们在该陨石中发现了一例另外

表 2 斜长石熔体池中熔长石的能谱成分分析结果成分 ${ }^{a}$

\begin{tabular}{|c|c|c|c|c|c|}
\hline 熔池号 & 1 号熔池 & 2 号熔池 & 3 号熔池 & 熔长石 & 斜长石 \\
\hline 分析数 & 3 & 3 & 3 & 平均 & 3 \\
\hline $\mathrm{SiO}_{2}$ & 67.7 & 68.8 & 68.4 & 68.3 & 68.1 \\
\hline $\mathrm{CaO}$ & 2.4 & 2.4 & 2.4 & 2.4 & 2.4 \\
\hline $\mathrm{Al}_{2} \mathrm{O}_{3}$ & 20.8 & 20.3 & 20.6 & 20.6 & 20.6 \\
\hline $\mathrm{Na}_{2} \mathrm{O}$ & 8.3 & 7.4 & 8.0 & 7.9 & 7.8 \\
\hline $\mathrm{K}_{2} \mathrm{O}$ & 0.8 & 1.1 & 0.6 & 0.8 & 1.1 \\
\hline 合计 & 100.0 & 100.0 & 100.0 & & 100.00 \\
\hline
\end{tabular}

a) 单位: $w t \%$

表 31 号斜长石熔体池中铬铁矿颗粒的能谱成分分析结果 $(\mathrm{wt} \%)$

\begin{tabular}{|c|c|c|c|c|c|}
\hline 颗粒尺寸 $(\mu \mathrm{m})$ & $11 \times 9$ & $7 \times 6$ & $3.5 \times 3$ & $3 \times 3$ & 平均 \\
\hline $\mathrm{MgO}$ & 2.6 & 2.6 & 3.1 & 2.9 & 2.8 \\
\hline $\mathrm{FeO}$ & 30.4 & 30.4 & 30.3 & 30.1 & 30.3 \\
\hline $\mathrm{TiO}_{2}$ & 2.8 & 3.1 & 3.3 & 2.9 & 3.0 \\
\hline $\mathrm{Al}_{2} \mathrm{O}_{3}$ & 5.7 & 5.3 & 5.2 & 6.1 & 5.5 \\
\hline $\mathrm{Cr}_{2} \mathrm{O}_{3}$ & 57.6 & 57.8 & 57.3 & 57.3 & 57.5 \\
\hline $\mathrm{V}_{2} \mathrm{O}_{3}$ & 0.9 & 0.8 & 0.8 & 0.7 & 0.8 \\
\hline 合计 & 100.0 & 100.0 & 100.0 & 100.0 & \\
\hline
\end{tabular}


表 42 号斜长石熔体池中铬铁矿颗粒的能谱成分分析结果 (wt\%)

\begin{tabular}{cccccccc}
\hline 颗粒尺寸 $(\mu \mathrm{m})$ & $5 \times 4$ & $5 \times 4$ & $5 \times 3$ & $4 \times 4$ & $3.5 \times 3$ & $3 \times 3$ & 平均 \\
\hline $\mathrm{MgO}$ & 3.1 & 2.5 & 3.1 & 2.5 & 3.0 & 2.9 & 2.9 \\
$\mathrm{FeO}$ & 30.2 & 30.3 & 30.0 & 30.2 & 30.1 & 30.6 & 30.2 \\
$\mathrm{TiO}_{2}$ & 2.9 & 2.4 & 2.9 & 2.3 & 2.9 & 2.4 & 2.6 \\
$\mathrm{Al}_{2} \mathrm{O}_{3}$ & 5.7 & 6.1 & 6.0 & 5.5 & 5.0 & 6.1 & 5.9 \\
$\mathrm{Cr}_{2} \mathrm{O}_{3}$ & 57.4 & 57.7 & 57.1 & 57.8 & 57.3 & 57.2 & 57.4 \\
$\mathrm{~V}_{2} \mathrm{O}_{3}$ & 0.7 & 1.0 & 0.9 & 0.7 & 0.7 & 0.8 & 0.8 \\
合计 & 100.0 & 100.0 & 100.0 & 100.0 & 100.0 & 100.0 & \\
\hline
\end{tabular}

表 53 号斜长石熔体池中铬铁矿颗粒的能谱成分分析结果 (wt \%)

\begin{tabular}{|c|c|c|c|c|c|}
\hline 颗粒尺寸 $(\mu \mathrm{m})$ & $9 \times 6$ & $6 \times 6$ & $3 \times 3$ & $3 \times 3$ & 平均 \\
\hline $\mathrm{MgO}$ & 3.2 & 3.0 & 3.0 & 3.1 & 3.1 \\
\hline $\mathrm{FeO}$ & 30.1 & 30.0 & 30.1 & 30.3 & 30.1 \\
\hline $\mathrm{TiO}_{2}$ & 2.9 & 3.1 & 2.8 & 2.9 & 2.9 \\
\hline $\mathrm{Al}_{2} \mathrm{O}_{3}$ & 5.3 & 5.9 & 6.1 & 5.5 & 5.8 \\
\hline $\mathrm{Cr}_{2} \mathrm{O}_{3}$ & 57.5 & 57.2 & 57.2 & 57.3 & 57.3 \\
\hline $\mathrm{V}_{2} \mathrm{O}_{3}$ & 1.0 & 0.8 & 0.8 & 0.9 & 0.9 \\
\hline 合计 & 100.0 & 100.0 & 100.0 & 100.0 & \\
\hline
\end{tabular}

产状的出溶铬铁矿, 呈 1 1.5 $\mu \mathrm{m}$ 宽、 50 100 $\mu \mathrm{m}$ 长的 片状体, 产在一个 $250 \mu \mathrm{m}$ 大小的自形橄榄石晶体中, 片状体主要沿橄榄石的 $\{100\}$ 分布，但相互间的间距 很大(图 5). 橄榄石晶体中可见到少量与冲击有关的 裂隙. EDS 分析给出该橄榄石的成分为 $\mathrm{SiO}_{2} 40.6 \mathrm{wt} \%$, $\mathrm{MgO} 35.9 \mathrm{wt} \%$, 和 $\mathrm{FeO} 23.5 \mathrm{wt} \%$ (表 6), 这与随州 陨石中橄榄石的平均成分很接近 ${ }^{[12]}$.

我们用 EDS 技术在 4 个测点上对橄榄石晶体中 出溶铬铁矿的化学成分进行了测定, 结果列在表 6 中. 由于片状体的厚度小于 $1.5 \mu \mathrm{m}, \mathrm{EDS}$ 的测量结果只能

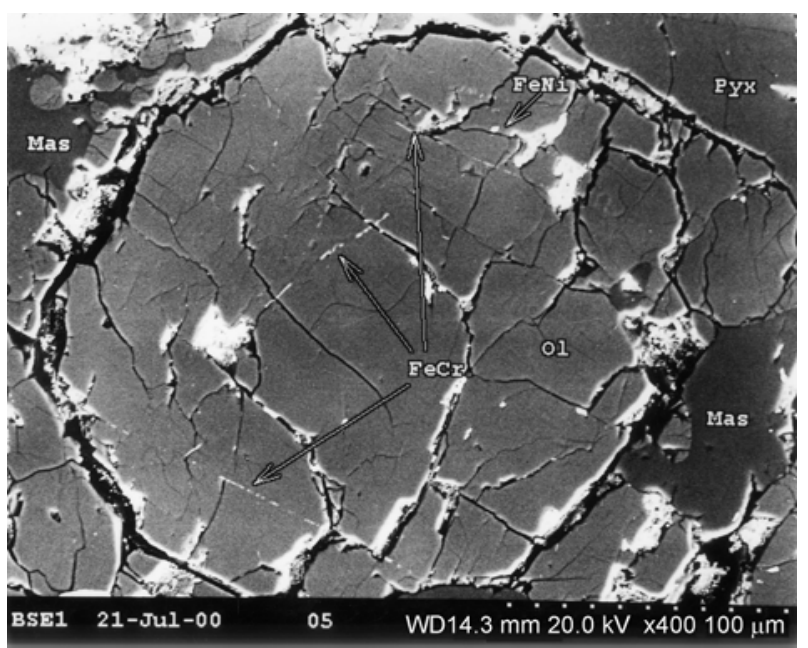

图 5 一个自形橄榄石 $(\mathrm{Ol})$ 颗粒的 BSE 图像 示橄榄石中呈间断线状产出的出溶铬铁矿 $(\mathrm{FeCr})$
表 6 自形橄榄石颗粒及出溶铬铁矿 4 个测点的能谱成分 分析结果 $(w t \%)$

\begin{tabular}{cccccc}
\hline & 橄榄石 & 测点 1 & 测点 2 & 测点 3 & 测点 4 \\
\hline $\mathrm{SiO}_{2}$ & 40.6 & 25.7 & 25.8 & 18.6 & 21.6 \\
$\mathrm{MgO}$ & 35.9 & 25.5 & 26.4 & 16.4 & 15.8 \\
$\mathrm{FeO}$ & 23.5 & 26.5 & 26.5 & 28.3 & 27.2 \\
$\mathrm{Cr}_{2} \mathrm{O}_{3}$ & n.d. & 21.3 & 21.3 & 32.7 & 31.5 \\
$\mathrm{Al}_{2} \mathrm{O}_{3}$ & n.d. & n.d. & n.d. & 4.0 & 3.9 \\
$\mathrm{~A}^{\mathrm{a}}$ 计 & 100.0 & 100.0 & 100.0 & 100.0 & 100.0 \\
\hline
\end{tabular}

反映铬铁矿和橄榄石的混合成分. 有趣的是, 测点 1 和测点 2 给出了非常相似的分析结果, 且 $\mathrm{Al}_{2} \mathrm{O}_{3}$ 均未 检出, 而测点 3 和测点 4 虽也给出了比较接近的分析 结果, 但 $\mathrm{Al}_{2} \mathrm{O}_{3}$ 的含量都高在 $4 \mathrm{wt} \%$ 左右. 由此我们 推测, 随州陨石橄榄石中出溶铬铁矿的成分并不均 一, $\mathrm{Al}_{2} \mathrm{O}_{3}$ 含量的变化明显. 考虑到该陨石中橄榄石 $\mathrm{Cr}_{2} \mathrm{O}_{3}$ 的平均含量只有 $0.03 \mathrm{wt} \%$, 基本上不含 $\mathrm{Al}_{2} \mathrm{O}_{3}{ }^{[12]}$, 要产生铬铁矿的出溶, 物质来源是个问题, 形成的时间也相当长. 因此, 我们认为上述铬铁矿线 状出溶物在随州陨石中的产出应属极个别现象，它 应该是陨石热变质作用的产物, 与后期的冲击变质 作用关系不大.

\section{3 谢氏超晶石的产状和成分}

随州陨石中冲击产生的铬铁矿高压多形有两种, 即具 $\mathrm{CaTi}_{2} \mathrm{O}_{4}$-结构(CT 相)的谢氏超晶石和尚待命名 
的、具 $\mathrm{CaFe}_{2} \mathrm{O}_{4}$-结构的 CF 相. 这两种结构相均属自 然界首次发现的超尖晶石结构矿物 ${ }^{[20 ~ 22]}$. 谢氏超晶 石这种铬铁矿的高密度相矿物在随州陨石中较为常 见. 最近, 我们用激光拉曼光谱仪对该陨石熔脉中所 能观察到的 20 多个铬铁矿颗粒进行了检测, 发现它 们全部都相变为 CT-结构的谢氏超晶石, 然而, CF-相 则较少见, 在随州陨石熔脉中我们没有观察到有 $\mathrm{CF}-$ 相的产出, 仅在熔脉边上两个部分高压相变的铬铁 矿颗粒中观察到.

谢氏超晶石在随州陨石中的已知产状有 2 种 ${ }^{[20,21]}$, 即熔脉中的单一相粗粒谢氏超晶石和熔脉 边上包含谢氏超晶石在内的铬铁矿三相颗粒. 不久 前, 我们在随州陨石的熔脉中, 又观察到谢氏超晶石 的第 3 种产状, 即由谢氏超晶石和一种硅酸盐矿物的 高压相组成的两相颗粒. 因前两种产状已有初步报 道, 在本节中仅作简要描述, 并补充较为详细的成分 数据, 重点则放在新近观察到的双相颗粒的产状和 成分上.

\section{1 谢氏超晶石在单相和三相颗粒中的产状和成 分}

与随州陨石未熔主体中铬铁矿多被强烈破碎的 情况相反, 产于熔脉中的粗粒谢氏超晶石均显示平 滑和很少裂纹的表面, 反射光下为浅灰色. 图 6(a)展
示熔脉内与林伍德石、镁铁榴石和玲根石等硅酸盐高 压相矿物密切共生的单相谢氏超晶石颗粒。应该指 出的是, 谢氏超晶石除主要以熔脉中单相粗颗粒产 出外, 还可在与熔脉直接接触的粗粒铬铁矿中观察 到, 说明哪里的压力和温度仍高到可使铬铁矿颗粒 靠近熔脉的一端产生高压相变. 图 6(b) 展示的就是一 个与随州陨石熔脉直接接触的三相铬铁矿颗粒, 它 由 3 种矿物条带组成, 即直接与熔脉接触的谢氏超晶 石内带、CF 相中间带和未发生相变的铬铁矿外带.

5 个谢氏超晶石颗粒的电子探针分析结果列于 表 7 中, 其中前 4 个为熔脉中单个谢氏超晶石颗粒, 第 5 个为三相颗粒中的谢氏超晶石. 从该表可以看出, 熔脉中和熔脉边上的谢氏超晶石在成分上是完全相 同的，与陨石未熔主体中铬铁矿的成分也相同，而我 们早先的研究结果已查明, 三相颗粒中间 CF 相的成 分与内带的谢氏超晶石和外带的铬铁矿也完全一 致 ${ }^{[21]}$, 这就说明, 单一相的谢氏超晶石和三相颗粒中 的谢氏超晶石与 $\mathrm{CF}$ 相, 都是在高压下直接由铬铁矿 经固态相变而形成的，因而没有其他元素被结合进 来.

\section{2 谢氏超晶石在两相颗粒中的产状和成分}

随州陨石熔脉中由冲击形成的高压相矿物中有 一种不寻常的产状，这就是我们新近发现的由谢氏
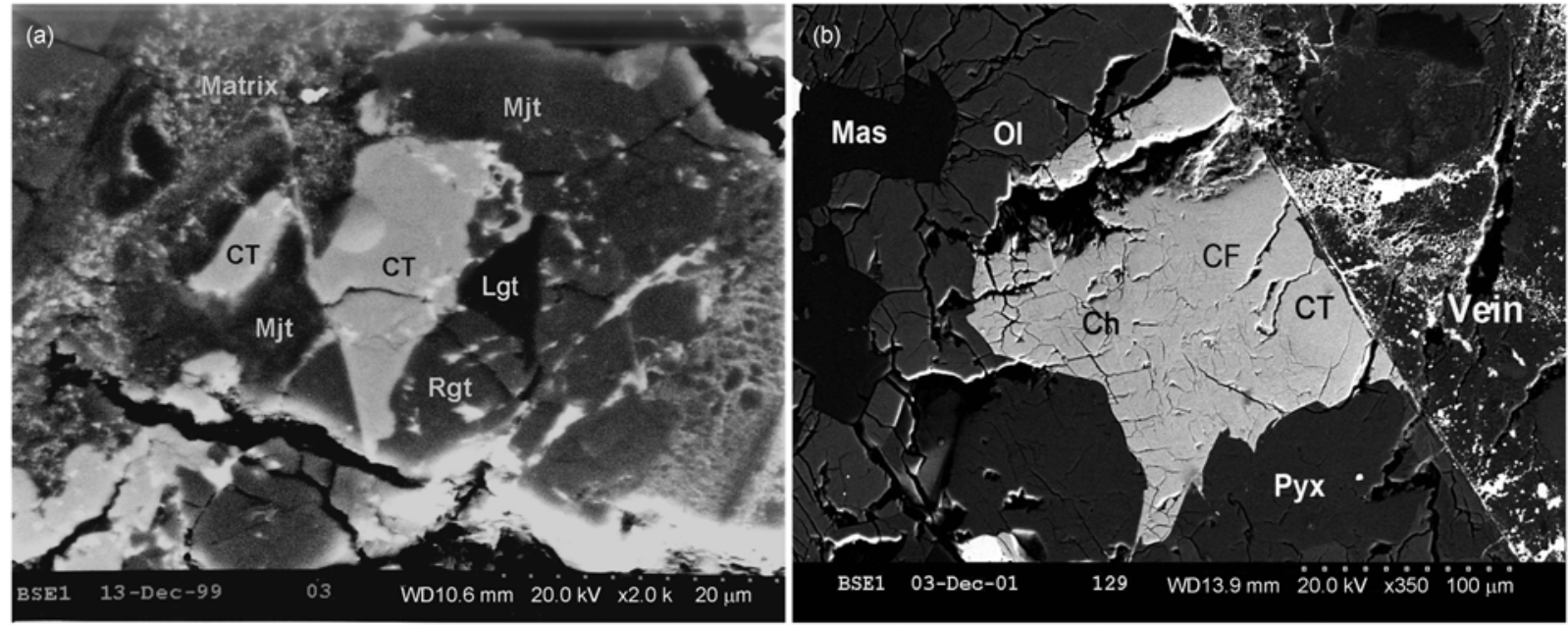

图 6 谢氏超晶石的 BSE 图像

(a) 随州陨石熔脉中的单个谢氏超晶石(CT)颗粒, 与林伍德石(Rgt)、镁铁榴石(Mjt)和玲根石(Lgt)等高压矿物环绕; (b) 与随州陨石熔脉边上 的一个铬铁矿颗粒已变成由三种矿物相组成的三相颗粒，即与熔脉直接接触的谢氏超晶石 (CT)内带、具 CF 结构相 (CF)的中带和未变的铬铁 矿(Ch)外带. 注意铬铁矿外带中面性裂隙发育，而其两种高压相内则少见裂陌. Matrix 表示熔脉基质 
表 7 随州陨石冲击熔脉中及熔脉边上谢氏超晶石的电子探针成分分析结果 ${ }^{a)}$

\begin{tabular}{ccccccc}
\hline 颗粒号 & 1 & 2 & 3 & 4 & 5 & 平均 \\
\hline $\mathrm{MgO}$ & 2.63 & 2.74 & 2.60 & 2.59 & 2.53 & 2.62 \\
$\mathrm{FeO}$ & 29.61 & 29.51 & 29.74 & 29.67 & 29.98 & 29.70 \\
$\mathrm{MnO}$ & 0.82 & 0.83 & 0.73 & 0.79 & 0.88 & 0.81 \\
$\mathrm{CaO}$ & n.d. & n.d. & n.d. & n.d. & n.d. & n.d. \\
$\mathrm{TiO}_{2}$ & 2.61 & 2.33 & 2.68 & 2.59 & 2.73 & 2.59 \\
$\mathrm{Cr}_{2} \mathrm{O}_{3}$ & 57.30 & 57.12 & 57.28 & 57.41 & 57.39 & 57.30 \\
$\mathrm{Al}_{2} \mathrm{O}_{3}$ & 5.94 & 5.87 & 5.93 & 5.96 & 5.99 & 5.94 \\
$\mathrm{~V}_{2} \mathrm{O}_{3}$ & 0.97 & 0.91 & 0.96 & 1.02 & 0.99 & 0.97 \\
合计 & 99.94 & 99.31 & 99.92 & 100.03 & 100.09 & 99.93 \\
\hline
\end{tabular}

a) 1 4 号为熔脉中单个谢氏超晶石颗粒; 5 号为与熔脉接触的一个三相颗粒中的谢氏超晶石

超晶石和一种硅酸盐的高压相组合而成的两相颗粒. 现已查明，与谢氏超晶石结合成两相颗粒的硅酸盐 高压相矿物, 分别有玲根石、林伍德石和镁铁榴石(图 7). 扫描电镜下观察, 所有两相颗粒的表面都比较光 滑, 未见有分带现象, 也未见有裂隙或裂缝, 这些两 相颗粒都不太大, 长约 20 25 $\mu \mathrm{m}$, 外形近似圆球或 液滴形. 有趣的是, 谢氏超晶石和硅酸盐高压相之间 的分界线均显示有轻度或中等程度的弯曲, 说明在 分界线部位曾发生过局部熔融. 我们对两相颗粒中 的 4 种高压相矿物, 都进行了激光拉曼探针的鉴定和 成分分析的验证. 在这些两相颗粒中, 谢氏超晶石均 给出 536,607 和 $666 \mathrm{~cm}^{-1}$ 的特征谱峰(图 8(a)), 该谱 图与熔脉中单相谢氏超晶石的完全相同. 两相颗粒 中的 3 种不同的硅酸盐高压相矿物的拉曼谱图(图 8(b) (d)), 也与熔脉中相对应的单一相的玲根石、林 伍德石和镁铁榴石等高压矿物完全相同 ${ }^{[12]}$.

我们用 EDS 技术测定了图 7(a)上一个两相颗粒 中谢氏超晶石和玲根石的成分, 结果列如表 8 . 为便 于比较, 我们同时也测定了这两种高压矿物在脉外 的母矿物一铬铁矿和斜长石的成分, 结果也列于表 8 中. 我们发现, 两相颗粒中谢氏超晶石的 $\mathrm{Al}_{2} \mathrm{O}_{3}$ 含量 (6.19 wt \%) 要高于其母矿物铬铁矿 (5.45 wt\%), 而 $\mathrm{Cr}_{2} \mathrm{O}_{3}$ 的含量 (56.48 wt \%) 则低于铬铁矿 (57.98 wt \%). 另一方面, 该两相颗粒中玲根石的 $\mathrm{Cr}_{2} \mathrm{O}_{3}$ 和 $\mathrm{FeO}$ 含量 (分别为 $0.32 \mathrm{wt} \%$ 和 $1.97 \mathrm{wt} \%$ ) 要高于其母矿物斜长石 (分别为 $0.03 \mathrm{wt} \%$ 和 $0.41 \mathrm{wt} \%$ ), 但其 $\mathrm{Al}_{2} \mathrm{O}_{3}$ 的含量 (19.98 wt \%)则比其母矿物斜长石 $(21.73 \mathrm{wt} \%)$ 明显偏 低. 这种成分上的变化说明, 两种矿物之间可能通过 高温扩散作用, 发生了元素的迁移, 即少量铬和铁从 铬铁矿向斜长石迁移, 而少量铝则从斜长石向铬铁 矿迁移, 其结果造成斜长石的高压相玲根石中铬和
铁含量的成倍增高, 而铬铁矿的高压相谢氏超晶石 中铝的含量也有一定增长.

类似的元素扩散情况也在谢氏超晶石和林伍德 石的两相颗粒中见到(表 9), 只是 $\mathrm{Al}_{2} \mathrm{O}_{3}$ 被 $\mathrm{FeO}$ 代替, 这是因为橄榄石通常不含 $\mathrm{Al}_{2} \mathrm{O}_{3}$. 从表 9 可知, 谢氏 超晶石的 $\mathrm{FeO}$ 含量 $(31.96 \mathrm{wt} \%)$ 比其母矿物铬铁矿 (30.39 wt \%)要高, 而 $\mathrm{Cr}_{2} \mathrm{O}_{3}$ 的含量 $(55.57 \mathrm{wt} \%$ ) 则明显 低于铬铁矿 (57.98 wt \%). 另一方面, 此类两相颗粒中, 林伍德石的 $\mathrm{FeO}$ 含量 $(19.95 \mathrm{wt} \%)$ 比其母矿物橄榄石 (22.35 wt\%) 明显偏低, 而 $\mathrm{Cr}_{2} \mathrm{O}_{3}$ 含量 $(0.58 \mathrm{wt} \%)$ 比其 母矿物橄榄石 $(0.03 \mathrm{wt} \%)$ 要高一个量级. 这进一步说 明, 元素的迁移和扩散同样存在与谢氏超晶石和林 伍德石的两相颗粒中, 少量铬从谢氏超晶石向林伍 德石迁移, 而少量铁则从林伍德石向谢氏超晶石迁 移.

应该指出的是, 由谢氏超晶石和镁铁榴石组成 的两相颗粒的成分分析结果, 与上述两种情况有着 明显的差别(表 10). 从总体上看, 这种两相颗粒中的 谢氏超晶石的成分与其母矿物铬铁矿十分接近, 其 $\mathrm{Al}_{2} \mathrm{O}_{3}$ 的含量 (5.69 wt \%) 略高于母矿物铬铁矿 (5.45 $\mathrm{wt} \%)$, 而 $\mathrm{Cr}_{2} \mathrm{O}_{3}$ 的含量(57.54 wt\%) 略低于母矿物铬 铁矿(57.98 wt\%). 然而, $\mathrm{FeO}$ 含量(31.32 wt \%) 比母矿 物铬铁矿 (30.39 wt \%) 要高, $\mathrm{MgO}$ 含量 $(2.00 \mathrm{wt} \%$ )则 低于母矿物铬铁矿 $(2.32 \mathrm{wt} \%)$. 另一方面, 两相颗粒 中美铁榴石的成分与其母矿物斜方辉石相比, 有了 明显的变化, 主要表现为 $\mathrm{SiO}_{2}$ 从 $55.78 \mathrm{wt} \%$ 剧降到 $50.71 \mathrm{wt} \%, \mathrm{MgO}$ 从 $29.31 \mathrm{wt} \%$ 下降到 $27.61 \mathrm{wt} \%$, 而 $\mathrm{Al}_{2} \mathrm{O}_{3}$ 从 $0.16 \mathrm{wt} \%$ 剧增到 $4.29 \mathrm{wt} \%, \mathrm{CaO}$ 从 $0.70 \mathrm{wt} \%$ 增高 $1.73 \mathrm{wt} \%, \mathrm{Cr}_{2} \mathrm{O}_{3}$ 从 $0.10 \mathrm{wt} \%$ 增高到 $0.91 \mathrm{wt} \%$, $\mathrm{FeO}$ 则从 $13.95 \mathrm{wt} \%$ 增高到 $14.76 \mathrm{wt} \%$. 以上结果表 明, 在这种类型的两相颗粒中, 谢氏超晶石和镁铁榴 

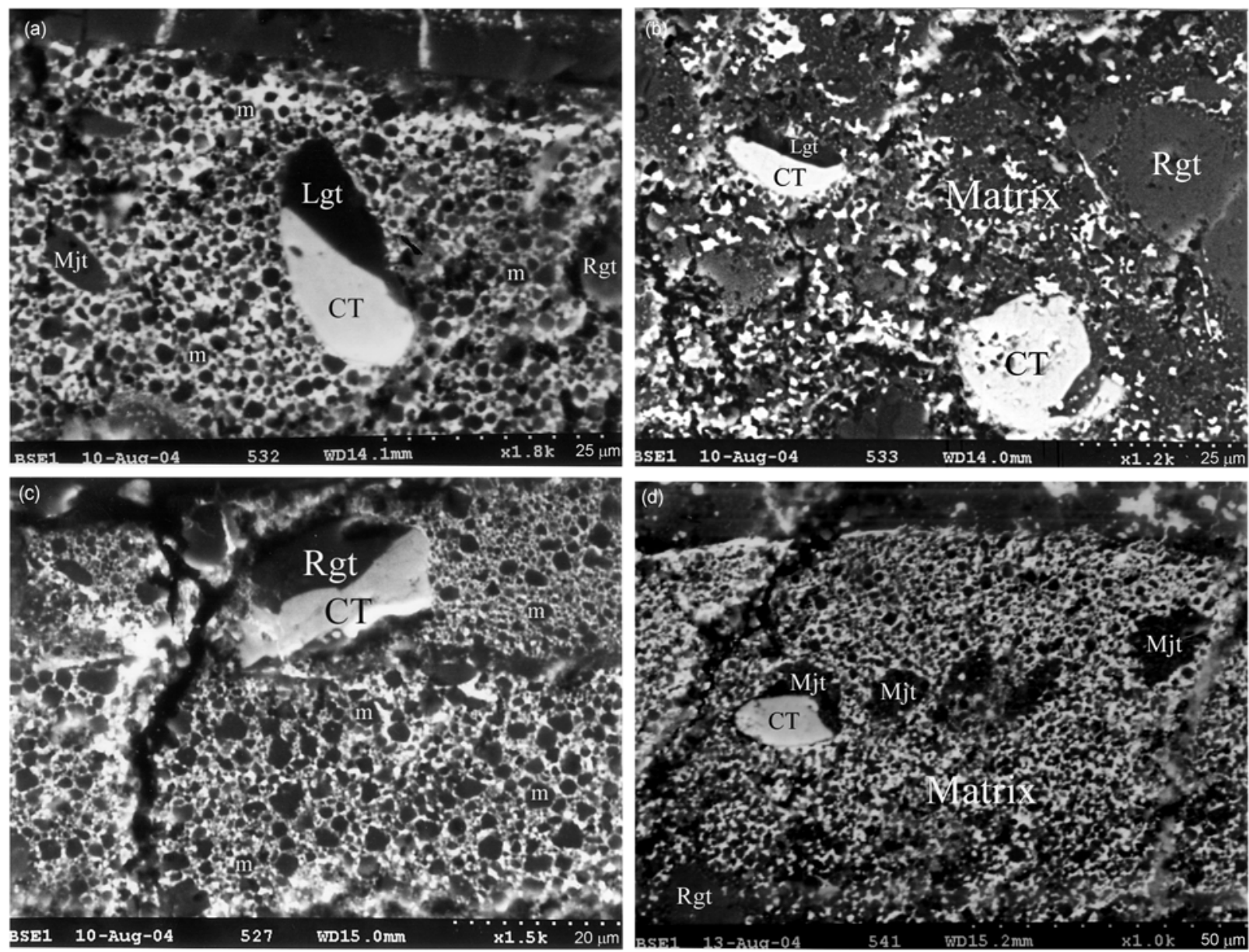

图 7 随州陨石冲击熔脉中两相颗粒的 BSE 图像

(a) 谢氏超晶石(CT)+玲根石(Lgt) 颗粒; (b) 另一谢氏超晶石+玲根石颗粒; (c) 谢氏超晶石+林伍德石(Rgt)颗粒; (d) 谢氏超晶石+镁铁榴石 (Mjt) 颗粒. 注意两相间的边界有轻微到中度的弯曲. $\mathrm{m}$ 表示镁铁-镁铝榴石(固熔体)

表 8 两相颗粒中谢氏超晶石和玲根石及其母矿物的化学成分 ${ }^{\text {a) }}$

\begin{tabular}{ccccc}
\hline & 陨石中的铬铁矿 & 两相颗粒中的谢氏超晶石 & 两相颗粒中的玲根石 & 陨石中的斜长石 \\
\hline $\mathrm{SiO}_{2}$ & & & 65.8 & 65.57 \\
$\mathrm{Al}_{2} \mathrm{O}_{3}$ & 5.5 & $6.2 \uparrow$ & $20.0 \downarrow$ & 21.73 \\
$\mathrm{MgO}$ & 2.3 & 2.4 & & 0.00 \\
$\mathrm{FeO}$ & 30.4 & 30.8 & $2.0 \uparrow$ & 0.41 \\
$\mathrm{CaO}$ & & & 2.3 & 2.12 \\
$\mathrm{MnO}$ & - & 0.7 & - & 0.02 \\
$\mathrm{TiO}_{2}$ & 2.9 & 2.4 & $0.3 \uparrow$ & 0.04 \\
$\mathrm{Cr}_{2} \mathrm{O}_{3}$ & 58.0 & $56.5 \downarrow$ & & 0.03 \\
$\mathrm{~V}_{2} \mathrm{O}_{3}$ & 0.9 & 1.0 & 8.4 & 8.87 \\
$\mathrm{Na}_{2} \mathrm{O}$ & & & 1.2 & 1.31 \\
$\mathrm{~K}_{2} \mathrm{O}$ & & 100.0 & 100.0 & 100.38 \\
合计 & 100.0 & & &
\end{tabular}

a) 斜长石为 EPMA 分析结果, 其他为能谱分析结果. 单位: wt \% 
表 9 两相颗粒中谢氏超晶石和林伍德石及其母矿物的化学成分 ${ }^{\text {a) }}$

\begin{tabular}{|c|c|c|c|c|}
\hline & 陨石中的铬铁矿 & 两相颗粒中的谢氏超晶石 & 两相颗粒中的林伍德石 & 陨石中的橄榄石 \\
\hline $\mathrm{SiO}_{2}$ & & & 39.9 & 38.3 \\
\hline $\mathrm{Al}_{2} \mathrm{O}_{3}$ & 5.5 & 5.9 & & \\
\hline $\mathrm{MgO}$ & 2.3 & 2.2 & 39.5 & 39.4 \\
\hline $\mathrm{FeO}$ & 30.4 & $32.0 \uparrow$ & $20.0 \downarrow$ & 22.3 \\
\hline $\mathrm{MnO}$ & - & 0.7 & & \\
\hline $\mathrm{TiO}_{2}$ & 2.9 & 2.5 & & \\
\hline $\mathrm{Cr}_{2} \mathrm{O}_{3}$ & 58.0 & $55.6 \downarrow$ & $0.6 \uparrow$ & 0.0 \\
\hline $\mathrm{V}_{2} \mathrm{O}_{5}$ & 0.9 & 1.1 & & \\
\hline 合计 & 100.0 & 100.0 & 100.0 & 100.0 \\
\hline
\end{tabular}

a) 均为能谱分析结果. 单位: wt $\%$

表 10 两相颗粒中谢氏超晶石和镁铁榴石及其母矿物的化学成分 ${ }^{\text {a) }}$

\begin{tabular}{ccccc}
\hline & 陨石中的铬铁矿 & 两相颗粒中的谢氏超晶石 & 两相颗粒中的镁铁榴石 & 陨石中的斜方辉石 \\
\hline $\mathrm{SiO}_{2}$ & & & $50.7 \downarrow$ & 55.8 \\
$\mathrm{Al}_{2} \mathrm{O}_{3}$ & 5.5 & 5.7 & $4.3 \uparrow$ & 0.2 \\
$\mathrm{MgO}$ & 2.3 & $2.0 \downarrow$ & $27.6 \downarrow$ & 29.3 \\
$\mathrm{FeO}$ & 30.4 & $31.3 \uparrow$ & $14.8 \uparrow$ & 13.9 \\
$\mathrm{CaO}$ & - & 0.7 & $1.7 \uparrow$ & 0.7 \\
$\mathrm{MnO}$ & 2.9 & 2.7 & & \\
$\mathrm{TiO}_{2}$ & 58.0 & $57.6 \downarrow$ & $0.9 \uparrow$ & 0.1 \\
$\mathrm{Cr}_{2} \mathrm{O}_{3}$ & 0.9 & 1.0 & & 100.0 \\
$\mathrm{~V}_{2} \mathrm{O}_{3}$ & 100.0 & 100.0 & 100.0 & \\
合计 & & & & \\
\hline
\end{tabular}

a) 均为能谱分析结果. 单位: wt \%

石之间的元素交换是很有限的, 仅有极少量的铝和 铁从镁铁榴石向谢氏超晶石迁移, 以及极少量的铬 从谢氏超晶石向镁铁榴石迁移. 然而, 镁铁榴石与其 母矿物斜方辉石在成分上的巨大差别, 说明有些镁 铁榴石的组分, 如 $\mathrm{Al}_{2} \mathrm{O}_{3}$ 和 $\mathrm{CaO}$ 可能是从周围的硅 酸盐冲击熔体捕获而来, 而镁铁榴石中有部分的 $\mathrm{SiO}_{2}$ 和 $\mathrm{MgO}$ 可能被冲击熔体捕获. 因此, 我们认为, 对于谢氏超晶石+镁铁榴石类型的两相颗粒来说, 存 在着两种类型的元素交换: 颗粒内两相之间的交换 和颗粒中熔融镁铁榴石与颗粒外富含 $\mathrm{Al}_{2} \mathrm{O}_{3}$ 和 $\mathrm{CaO}$ 但 相对贫 $\mathrm{SiO}_{2}$ 和 $\mathrm{MgO}$ 的硅酸盐熔体之间的组分交换.

\section{4 讨论}

我们在随州陨石未熔主体中观察到铬铁矿的 3 种产状, 即单一相粗粒铬铁矿、斜长石熔体池中的铬 铁矿集合体簇团和橄榄石晶体中的片状出溶铬铁矿. 此外, 我们还观察到与随州陨石中的熔脉有关的 3 种 谢氏超晶石产出类型, 即熔脉中的单一相谢氏超晶
石颗粒、与熔脉直接接触的谢氏超晶石 $+\mathrm{CF}$ 相 + 铬铁 矿的三相颗粒，以及熔脉中的谢氏超晶石+硅酸盐高 压相的两相颗粒. 我们认为, 铬铁矿和谢氏超晶石的 这些产状特征, 均与随州陨石的 $P-T$ 历史有关. 根据 前人的高温高压实验结果 ${ }^{[23]}$ 和随州陨石未熔主体中 矿物的冲击变质特征, 如橄榄石出现镶嵌块状消光 和多数斜长石已转变为熔长石 ${ }^{[12,21]}$, 以及将熔脉中 产出的两个高压矿物组合与寺巷口陨石熔脉中两个 高压矿物组合相比较 ${ }^{[12,21,24]}$, 我们曾推定该陨石未熔 主体经受过 20 24 GPa 的冲击压力和 $1000^{\circ} \mathrm{C}$ 的高温, 而熔脉则经受过 $18 \sim 24 \mathrm{GPa}$ 的冲击压力和高达 $1800 \sim 2000^{\circ} \mathrm{C}$ 的高温, 我们取 $24 \mathrm{GPa}$ 作为陨石主体和 熔脉所受压力的上限, 并解释了熔脉温度大大高于 陨石主体的主要原因与局部的剪切磨擦生热有关 ${ }^{[12]}$. 正是由于熔脉温度的急剧升高和有一定的保压时间, 引起脉中的矿物发生固态相变和随后从冲击熔体中 结晶出细粒的高压矿物组合来 ${ }^{[14,24]}$. 另一方面, 由于 铬铁矿的熔点 $\left(\geqslant 2000^{\circ} \mathrm{C}\right)$ 大大高于陨石未熔主体所 受的温度 $\left(1000^{\circ} \mathrm{C}\right)$, 故不管其产状如何, 陨石未熔主 


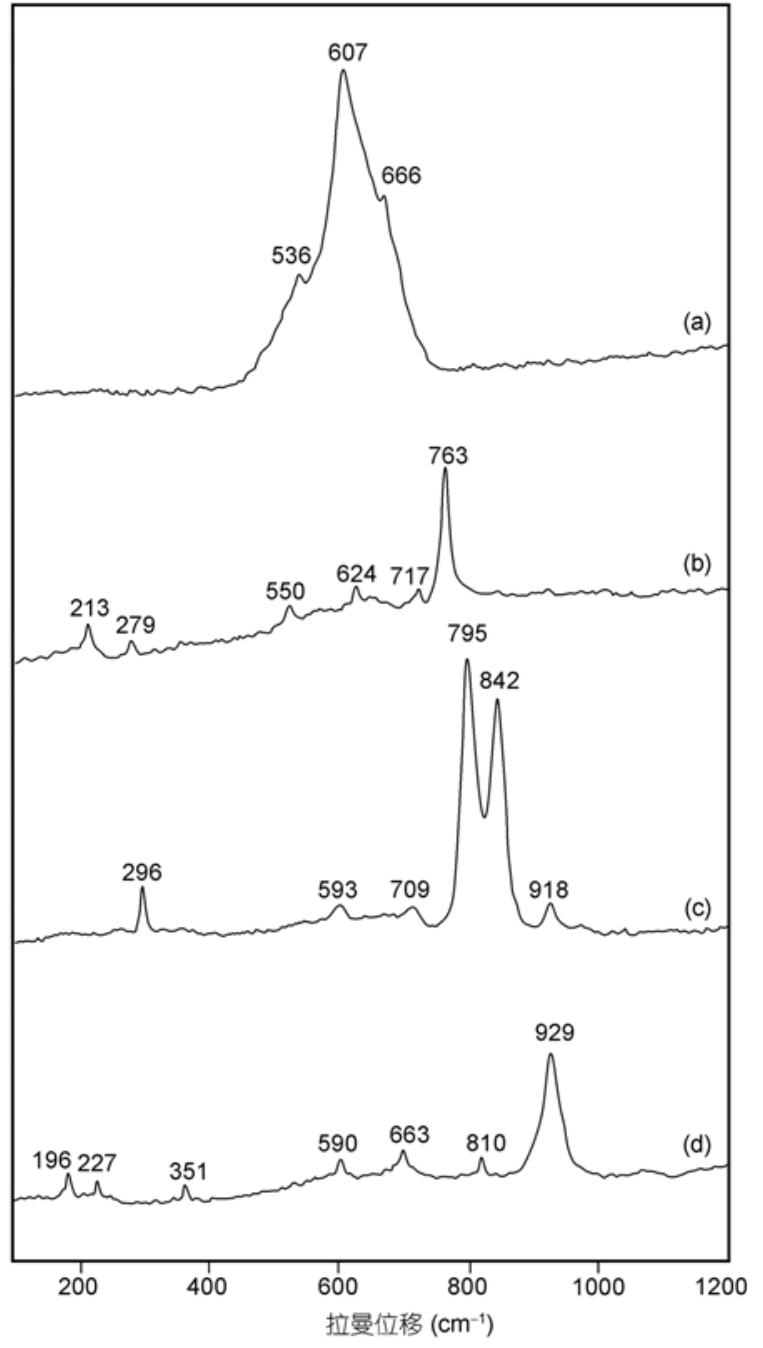

图 8 两相颗粒中高压矿物的拉曼谱图

(a) 谢氏超晶石; (b) 玲根石; (c) 林伍德石; (d) 镁铁榴石

体中的铬铁矿颗粒或熔长石中的铬铁矿碎片, 在物 理和化学性质上都比较稳定，成分保持不变.

关于普通球粒陨石中斜长石内铬铁矿集合体簇 团的成因, 存在着 3 种不同的观点. 早在上世纪 60 年代, Ramdohr ${ }^{[1]}$ 认为铭铁矿和斜长石是在太阳星云 时期同时冷凝结晶形成铬铁矿-斜长石球粒，而该类 型铬铁矿就产在这种球粒或球粒的碎块中, 它们与 陨石后期的冲击变质作用无关. Rubin ${ }^{[3]}$ 于 2003 年在 研究了 76 个平衡的 H, L 和 LL 群球粒陨石中铬铁矿斜长石组合后, 提出了铭铁矿-斜长石交互生长的观 点, 他认为冲击受热后的斜长石能熔化其邻近的铬 铁矿, 而富铬铁矿和富斜长石的熔体被挤压进周围
硅酸盐矿物颗粒的裂缝内, 铬铁矿在裂缝中结晶, 富 斜长石的熔体则向前流动并就近形成富斜长石的熔 体池. 我们在详细研究了随州陨石未熔主体中斜长 石熔体池内微小铬铁矿碎片的产出特征后, 曾提出 有别于上述两种认识的观点, 我们认为, 不少熔长石 中微小铬铁矿集合体簇团系冲击作用的产物, 是由 陨石中早先的粗粒铬铁矿受冲击碎裂后, 被流动着 的斜长石熔体捕获而形成的 ${ }^{[12]}$.

当然, Ramdohr 的球粒成因观点可以用来对随州 陨石中的少量斜长石内铬铁矿集合体簇团的成因进 行解释, 特别是那些较为圆形或椭圆形斜长石熔体 池中的铬铁矿簇团, 但用其来解释该陨石中大多数 铬铁矿簇团的成因是不妥的，原因有三：(1) 王人镜 等 ${ }^{[10]}$ 曾对 5 个随州陨石薄片进行了研究, 并统计出各 类球粒在陨石中的体积含量为 $13.23 \%$, 他们描述了 球粒的 10 种结构类型, 并展示了 16 张球粒的显微照 片，但他们既没有观察到铬铁矿球粒，也没有见到 Ramdohr 所称的铬铁矿-斜长石球粒或球粒的碎块 ${ }^{[10]}$. 我们也对多块随州陨石的光薄片做过观察, 同样没 有发现过铬铁矿-斜长石球粒或球粒的碎块, 也未见 到单颗粒的未熔斜长石中有铬铁矿包裹体的存在. (2) 在光学和扫描电子显微镜下, 随州陨石未熔主体中 的熔长石表面平滑, 大多以充填于其他硅酸盐矿物 隙间的不规则形的细脉体、分脉体或熔池的形式产出 (图 4(a)), 显示出其冲击熔融成因和熔体受挤压流动 的特征. (3) 杂乱分散在熔长石中的大多数铬铁矿碎 片具有较圆滑或不规则外形, 早先的粗铬铁矿颗粒 的局部轮廓和粒内裂隙, 在较大的铬铁矿碎片中还 清晰可见(图 2(b)), 这就为其冲击碎裂后被熔长石捕 获的成因机制提供了佐证.

Knot 等 ${ }^{[25]}$ 曾指出, 普通球粒陨石中的铬铁矿球 粒具有状粒、斑状或复合结构, 并由包埋在富斜长石 基质中的铬铁矿颗粒组成. 他们的报告称，铬铁矿। 尖晶石的比值在 0.2 0.9 的很大范围内变化, 铬铁矿 的 $\mathrm{FeO}$ 含量范围为 $20 \mathrm{wt} \%$ 30 wt \%, 尖晶石的 $\mathrm{FeO}$ 含量范围为 $12 \mathrm{wt} \%$ 25 wt $\%$, 而铬铁矿的 $\mathrm{TiO}_{2}$ 含量 则高达 $2 \mathrm{wt} \%$. 基质中斜长石的成分也变化很大, $\mathrm{Ab}$ 为 $40 \mathrm{~mol} \% \sim 90 \mathrm{~mol} \%$ 和 $\mathrm{Or}$ 为 $1 \mathrm{~mol} \% \sim 55 \mathrm{~mol} \%$. 遗憾的 是, 我们在随州陨石未熔主体中没有发现过任何铬 铁矿球粒，但对于 Knot 等 ${ }^{[25]}$ 包埋在富斜长石基质中 的铬铁矿颗粒, 和随州陨石中包埋在熔长石内的铬 铁矿碎片之间在化学组成上的巨大差别, 是很容易 
解释的, 因为普通球粒陨石中的铬铁矿球粒是在太 阳星云凝聚期间形成的，而熔长石中的铬铁矿颗粒 碎片则主要与普通球粒陨石的后期冲击变质作用有 关.

Rubin $^{[3]}$ 的铬铁矿-斜长石交互生长的观点, 对于 那些冲击温度高到足以引起斜长石和铬铁矿都发生 熔融的情况是合理可信的, 然而, 这样的情况非常少 见, 因为铬铁矿是一种耐火氧化物矿物, 其熔点比斜 长石 $\left(\sim 1000^{\circ} \mathrm{C}\right)$ 要高很多, 故耐火的铬铁矿是很难被 冲击受热的斜长石熔化的. 由此可以看出, 包裹在斜 长石中的铬铁矿, 在化学成分上也应保持不变. 事实 上, 随州陨石中包裹在斜长石熔体池内的大量铬铁 矿碎片的成分是完全相同的, 说明它们化学上很稳 定, 也从未熔融过, 其颗粒度虽小到只有 $0.2 \mu \mathrm{m}$, 但 铬铁矿和斜长石两相间并没有发生元素的交换. 此 现象再次为我们提出的冲击碎裂和被熔体捕获机制 提供了有力的旁证.

Funamori 等 ${ }^{[26]}$ 曾在 $\mathrm{MgAl}_{2} \mathrm{O}_{4}$ 的高压实验中, 发 现其转变为超尖晶石相时, 有一个中间分解过程, 但 随州陨石中铭铁矿和谢氏超晶石的产状和成分特征, 支持了谢氏超晶石是由铬铁矿经固态相变直接形成 的, 我们没有发现铬铁矿中间分解过程的存在, 因为
随州陨石熔脉的峰温 $\left(1800 \sim 2000^{\circ} \mathrm{C}\right)$ 要比铬铁矿的分 解温度低.

在谢氏超晶石与硅酸盐矿物高压相组成的两相 颗粒中，两种矿物在成分上均与单一相粗粒谢氏超 晶石和硅酸盐母矿物有一定的区别, 两相间出现了 一定程度的组分交换，硅酸盐矿物的成分变化比谢 氏超晶石更明显一些，估计这主要与高温扩散有关， 也与这两类矿物的密度和熔点不同有关. 铬铁矿的 密度为 $4.43 \mathrm{~g} / \mathrm{cm}^{3}$, 比斜长石的 $2.6 \mathrm{~g} / \mathrm{cm}^{3}$ 、橄榄石和 斜方辉石的 $3.2 \sim 3.3 \mathrm{~g} / \mathrm{cm}^{3}$ 都要高, 它们高压相变后, 谢氏超晶石的密度为 $5.63 \mathrm{~g} / \mathrm{cm}^{3[20]}$, 而玲根石、林伍 德石和镁铁榴石的密度都低于 $3.80 \mathrm{~g} / \mathrm{cm}^{3}$. 铬铁矿和 谢氏超晶石都是高熔点和高阻抗物质, 比硅酸盐矿 物在物理和化学上更稳定，在界面上更容易将冲击 波反射到硅酸盐矿物中，从而引起后者的局部熔融. 因此，我们认为，用这一机制可以较好地解释两相颗 粒中矿物化学的复杂性和两相间边界线的轻到中度 弯曲. 对谢氏超晶石+镁铁榴石类型的两相颗粒来说, 情况可能更复杂一些，因为该两相颗粒中的镁铁榴 石已完全熔融, 并与熔脉基质中富含 $\mathrm{Al}_{2} \mathrm{O}_{3}, \mathrm{CaO}$ 和 贫 $\mathrm{SiO}_{2}, \mathrm{MgO}$ 的硅酸盐熔体有一定的混合, 因而产生 了明显的组分交换.

\section{参考文献}

1 Ramdohr P. Chromite and chromite chondrules in meteorites-I. Geochim Cosmochim Acta, 1967, 31: 1961-1967

2 Ramdohr P. The Opaque Minerals in Stony Meteorites. Amsterdam: Elsevier Press, 1973. 245

3 Rubin A E. Chromite-plagioclase assemblages as a new shock indicator: Implications for the shock and thermal histories of ordinary chondrites. Geochim Cosmochim Acta, 2003, 67: 2695-2709

4 Brearley A J, Jones R H. Chondritic meteorites. Rev Mineral, 1998, 36: 6-37

5 Tassin W. On meteorite chromites. Proc U S Nat Mus, 1908, 34: 685-690

6 Bunch T E, Keil K, Snetsinger K G. Chromite composition in relation to chemistry of ordinary chondrites. Geochim Cosmochim Acta, 1967, 31: 1569-1582

7 Jérémine E, Orcel J, Sandréa A, et al. La meteorite de Dosso (République du Niger). Geochim Cosmochim Acta, 1964, 28: 1119-1124

8 Buseck P K, Mason B, Wiik H B. The Farmington meteorite-mineralogy and chemistry. Geochim Cosmochim Acta, 1966, 30: 1-8

9 Snetsinger K G, Keil K, Bunch T E. Chromite from “equilibrated "chondrites. Am Miner, 1967, 52: 1322-1331

10 王人镜, 李肇辉. 随州陨石综合研究. 武汉：中国地质大学出版社, 1967. 1-62

11 王道德. 中国陨石导论. 北京：科学出版社, 1993

12 Xie X D, Chen M, Wang D Q. Shock-related mineralogical features and P-T history of the Suizhou L6 chondrite. Eur J Mineral, 2001, 13: $1177-1190$

13 谢先德, 陈鸣, 王德强. 随州陨石冲击熔脉中的 $\mathrm{NaAlSi}_{3} \mathrm{O}_{8}$-锰钡矿和其他高压相矿物. 科学通报, 2001, 46: 506-510

14 Xie X D, Chen M, Dai C D, et al. A comparative study of naturally and experimentally shocked chondrites. Earth Planet Sci Lett, 2001, 187: $345-356$ 
15 Xie X D, Minitti M E, Chen M, et al. Natural high-pressure polymorph of merrillite in the shock vein of the Suizhou meteorite. Geochim Cosmochim Acta, 2002, 66: 2439-2444

16 Xie X D, Minitti M E, Chen M, et al. Tuite, $\gamma-\mathrm{Ca}_{3}\left(\mathrm{PO}_{4}\right)_{2}$, a new phosphate mineral from the Suizhou L6 chondrite. Eur J Mineral, 2003, 15: $1001-1005$

17 谢先德, 束今赋, 陈鸣. 随州陨石熔脉中微粒矿物的同步辐射 X 射线衍射原位研究. 中国科学 D 辑: 地球科学, 2004, 34: 1129-1134

18 谢先德, 陈鸣, 王德强, 等. 动态高压下斜长石的熔融和玻璃化研究. 岩石学报, 2006, 24: 503-509

19 Chen M, Xie X D, El Goresy A. A shock-produced (Mg,Fe) $\mathrm{SiO}_{3}$ glass in the Suizhou meteorite. Meteor Planet Sci, 2004, 39: 1797-1808

20 Chen M, Shu J F, Xie X D, et al. Natural $\mathrm{CaTi}_{2} \mathrm{O}_{4}$-structured $\mathrm{FeCr}_{2} \mathrm{O}_{4}$ polymorph in the Suizhou meteorite and its significance in mantle mineralogy. Geochim Cosmochim Acta, 2003, 67: 3937-3942

21 Chen M, Shu J F, Mao H K, et al. Natural occurrence and synthesis of two new postspinel polymorphs of chromite. Proc Natl Acad Sci USA, 2003, 100: 14651-14654

22 陈鸣, 束今赋, 毛河光. 谢氏超晶石: 一种 $\mathrm{FeCr}_{2} \mathrm{O}_{4}$ 高压多形新矿物. 科学通报, 2008, 53: 2060-2063

23 Agee C B, Li J, Shannon M C, Circone S. Pressure-temperature phase diagram for Allende meteorite. J Geophys Res, 1995, 100: $17725-17740$

24 Chen M, Sharp T G, E1 Goresy A, et al. The majorite-pyrope+magnesiowustite assemblage: Constrains on the history of shock veins in chondrites. Science, 1996, 271: 1570-1573

25 Knot A N, Ivanova M A, Wasson J T. The origin of chromatic chondrules and the volatility of Cr under a range of nebular condensats. Earth Planet Sci Lett, 1991, 119: 569-584

26 Funamori N, Jeanloz R, Nguyen J H, et al. High-pressure transforms in $\mathrm{MgAl}_{2} \mathrm{O}_{4}$. J Geophys Res, 1998, 103: 20813-20818 